\title{
LOS VIDEOJUEGOS DEL BICENTENARIO DE LA INDEPENDENCIA DE MÉXICO. Usos y abusos de la identidad, el héroe y la historia
}

\author{
Manuel Jesús GONZÁLEZ MANRIQUE \\ Universidad Autónoma del Estado de Hidalgo (México) \\ mjgman@gmail.com
}

\begin{abstract}
MEXICAN INDEPENDENCE BICENTENNIAL'S VIDEO GAMES. Identity uses and abuses, the hero and history
\end{abstract}

Resumen: En este artículo se analiza la continuidad iconográfica y discursiva de la historia oficial en los productos culturales realizados para la celebración del Bicentenario de la Independencia de México en 2010.La efeméride contó con una masiva producción de estos, entre los que destacan como novedad los videojuegos diseñados para un público infantil y juvenil. Posicionándonos en la postura integrada de Walter Benjamin y Umberto Eco y los estudios sobre la era neobarroca de Omar Calabrese, analizaremos la imagen de la Independencia a través de la reiteración de las representaciones del Padre de la Patria, Miguel Hidalgo, en las diferentes épocas de gestación de su figura mitológica hasta llegar a los videojuegos realizados en 2010. De esta forma, proponemos discutir con las posiciones académicas que sostienen un uso adecuado de los medios por parte de las estructuras gubernamentales frente a la estética de la repetición formulada por Omar Calabrese en La era neobrarroca.

Abstract: The objective of this article is to examine the iconographic and discursive continuity inmerse in oficial history within the cultural products designed for Mexican Independence Bicentennial's celebration, that took place in 2010 . The event had a massive production of cultural ítems, which include the outstanding innovative video games for kids and teenagers. This work is mainly based on the theoretical approach created by Walter Benjamin and Umberto Eco and, furthermore, it is enriched with the studies about Neobaroque era by Omar Calabrese. Since Miguel Hidalgo has been considered the father of the Independence, we are going to analyze the image of the movement throughout Hidalgo's reiterated representations during several stages that start with the creation of his mythical image until the production of video games in 2010. In this way, we propose to discuss with the academical postures that hold an appropiate usage of the media by the gubernamental structures versus the aesthetic of repetition devised by Omar Calabrese in the Neobaroque Era.

Palabras clave: Miguel Hidalgo; Videojuegos; Identidad Nacional; Historia de México; Héroe Nacional Video Games; National Identity; History of Mexico; National Hero 


\section{Introducción}

"No estoy muy lejos de pensar que en nuestras sociedades la historia sustituye a la mitología y desempeña la misma función" (Lévi-Strauss, 2002).

El año 2010 fue para los Estados Unidos Mexicanos una fecha llena de expectativas festivas y de reflexión identitaria. En ese año se conmemoraba el bicentenario de la insurrección que condujo a la Independencia de México (1810), y el centenario de la Revolución Mexicana (1919); dos hitos en la historia del país cargados de significado y controversias. Si bien México no nace como Estado Nación moderno hasta 1821, la historia oficial ha convertido a Miguel Hidalgo en el padre de la Patria por aclamación popular y apoyo massmediático.

Con el PAN en el poder y ante la expectativa, el Estado invirtió pingües recursos monetarios y humanos en el doble festejo, eventos cívicos y culturales de diversa índole vistieron las calles de todos los rincones de la República. Ante tal despliegue de medios públicos al que hemos de agregarle los privados, que no fueron pocos, tanto el estado como los medios de comunicación exhortaron a la ciudadanía a recordar y honrar los mitos y padres fundadores de la patria, y principalmente a Miguel Hidalgo y Costilla.

Las bases donde se sustentó la difusión social de la efeméride fueron el estado, la academia y los medios de comunicación; siendo estos últimos, en sus diversos formatos, determinantes a la hora de "dictar" como se debía representar el pasado independentista, dentro del marco habitual de la "historia oficial".

$\mathrm{Si}$ atendemos a los objetos culturales producidos durante el evento encontramos una estética de la repetición que eterniza tanto la iconografía como el discurso oficial. Un mensaje vacío de contenido complejo y una adaptación estética a los nuevas sociedades y por ende a sus mercados, al gusto de la época (Calabrese, 1999).

Pero ¿Cómo utilizó el Estado y las empresas privadas sus herramientas para re-dibujar, subrayar, en la contemporaneidad la imagen de los padres de la patria doscientos años después de los hechos? ¿Cómo reubicarlos en una sociedad globalizada con sus propios medios y códigos de comunicación?

Mucho también se ha debatido tanto desde los medios como desde la academia sobre el resultado político o intelectual del evento, pero poco sobre la intoxicación de productos relacionados para el evento y su contenido. Los estudios hasta ahora realizados sobre estos productos culturales, como el de Alan Rodríguez sobre la película "Hidalgo. La historia jamás contada (Serrano, 2010) o el de Ramírez Zaragoza sobre el videojuego Memorias de una nación aseguran una modernización en el mensaje y una adecuación a las necesidades culturales y educativas de la población. Pero ¿acaso solo el uso de un nuevo soporte supone la modernización? ¿Qué ocurre con el contenido estético y el discurso?

Si partimos de la postura integrada de Walter Benjamin (Benjamin, W., Weikert, A. E., \& Echeverría, 2003) y Umberto Eco (Eco, 1999) y los beneficios de los medios de masas para la educación social vemos la importancia de estos productos para la cultura visual y el asentamiento de ideas. Por otra parte, la posición de Omar Calabrese, con la que considera que el análisis de una obra contiene el "gusto de una época", así como los efectos de la repetición y exceso veremos cómo tanto imagen como mensaje quedan petrificados pasando de la celulosa de los libros decimonónicos al bit.

Desde esta óptica haremos un repaso a los productos culturales y en especial a la novedad de la época, el videojuego, que constituye la gran industria cultural actual, tanto en consumo como en réditos económicos. Para ello se analizan, según su género, los tres videojuegos que se pusieron a disposición de la sociedad mexicana a disposición del público infantil y juvenil para informarles del porqué del macroevento. 


\section{Historia y mito en América Latina}

Si algo distingue a México y, por extensión a toda América Latina es la presencia del impacto de la Historia en el devenir cotidiano.

En palabras de Luis González "Exagerando un poco, cabría llamar a los libros de historia de la escuela mexicana Vidas de hombres ilustres mexicanos y Vidas de los inocuos imperialistas extranjeros. Se trata de textos que no sólo desprenden de su contexto histórico los hombres y las hazañas edificantes para hacernos patriotas a carta cabal, sino que embellecen o afean a los personajes y los hechos con embustes literarios. Allí están las caricaturas de Cuauhtémoc, Cortés y la Conquista; Calleja, Morelos y la revolución de independencia; Juárez, Maximiliano y la reforma liberal, para botones de muestra de cómo se hacen atractivos los personajes oriundos de esta tierra, y repelentes las figuras que tuvieron la desgracia de nacer en otras latitudes, y de cómo se adorna y aplaude la conducta de los nuestros y se reciben con rechifla los haceres extraños." (González, 2006)

La fuerza con que se propagó la historia oficial hizo que sólo en los medios académicos y algunos medios especializados el debate llegara a la hondura necesaria como para servir de fiel ilustración de la complejidad de la época ${ }^{1}$. Pero por otro lado, la estancias institucionales y la mayor parte de los medios de divulgación impresos subrayaron la "historia oficial" y la estética decimonónica del bronce de las estatuas de la independencia que plagan México llegó a los pixeles de las modernas tabletas pasando obligatoriamente por los libros gratuitos de texto editados por la Secretaría de Educación pública

Un estudio a tener en cuenta es el realizado por Hugo Arturo Cardoso Vargas, en el que estudia la "mexicanidad" en los libros de texto gratuitos de la Secretaría de Educación Pública. Toma categorías como nacionalismo y patriotismo a través del discurso contenido en seis libros seleccionados y analizados bajo el modo de Berelson (1984) con sus cinco niveles - portada, índice, unidad didáctica, mensajes aislados y el nivel de cantidad y calidad. Tras la investigación podemos concluir cómo desde el punto de vista iconográfico y de cantidad, la figura más resaltada es la de Miguel Hidalgo como símbolo del México moderno (Cardoso Vargas, 2006). Esta respondería a la siembra iconográfica previa al evento que nos ocupa, pues los resultados son de 2006, por lo que ilustra el tipo de contenido dirigido al mismo público al que posteriormente van a ir dirigidos los productos lúdicos digitales.

\section{El nacionalismo como identidad}

\section{El nacionalismo como identidad: el caso de México}

Durante el siglo XVIII, y guiado por las nuevas corrientes ideológicas ilustradas, se fueron sucediendo en la Nueva España una serie de acontecimientos que apuntaban a una reestructuración "profunda" de las bases del Antiguo Régimen.

Protagonistas de estos hechos fueron por tradición clérigos; en 1755 Francisco Xavier Clavijero escribe su "Historia Antigua de México" como respuesta a las apreciaciones de dos ilustrados: el francés George Louis Leclerc, conde de Bufón (1707-1788), que aseveraba que América se encontraba en un estado de evolución retardada en lo biológico, lo que incluía a los humanos y resaltando este retardo en los indígenas. Por otra parte del Prusiano

\footnotetext{
1 En los años anteriores al evento, revistas como Nexos o Letras Libres abrieron debates acerca del devenir de México desde la Independencia que enriquecieron el debate académico posterior. Por su parte, las universidades y centros de investigación se dieron a la tarea de realizar diversos eventos -congresos, coloquios, exposiciones..- que mantuvieron, en la mayoría de los casos un nivel discursivo y crítico de alta calidad. También la televisión tuvo sus programas de análisis histórico, social y antropológico, entre los que destacaremos "Discutamos México", emitido por el Canal 22 durante el año de las efemérides y donde se hizo un análisis de la historia de México desde posturas más abiertas y multidisciplinarias.
} 
Cornelius Franciscus de Paw (1739-1799) opinando que era un zona inapropiada para el desarrollo humano ponienco como ejemplo a los "perezosos mentales" indígenas y a la degradación biológica del mestizo, que no era más que un europeo contaminado.

El afán ilustrado de Clavijero fue seguido por el fraile dominico Servando Teresa de Mier (1763-1827), que aseguraba que Santo Tomás había evangelizado a los indígenas con el nombre de Quetzalcoatl con lo que la tendencia europea de mirar hacia un ilusorio pasado grecorromano, en la Nueva España se tornó a una mirada e intento de conexión con el pasado prehispánico.

Las críticas a la corona española de Fray Servando Teresa de Mier fueron la base para fundamentar el derecho de la Nueva España a la independencia, con un marcado sentimiento antiespañol que caracterizó el nacionalismo de la época de la independencia (Florescano, 1989: 40).

Pero finalmente fue Carlos María de Bustamante (1774-1848) el que estableció un nexo de unión histórica entre el pasado prehispánico y el presente independiente. Partiendo se sus textos, el concepto de nación que germina de la insurgencia aúna el proyecto de nación independiente a la idea de "nación indígena" anterior a la conquista. Este impulso que unía la mentalidad mítica hacia el momento del génesis, cuando la creencia en el mito de la nación indígena original permitía imaginar una nación virgen de lo europeo. (Florescano, 1989: 37).

Las apreciaciones de los viajeros románticos del siglo XIX tampoco ayudaron a la dignificación del indígena. Humboldt los tachaba de "casta más miserable [...] las heces del pueblo" (Humboldt, 1975: 60-61); lo cual fue repetido como de diversas autoría por los posteriores viajeros que encontraban imposible que los indígenas del momento pudieran ser los descendientes de los opulentos y espléndidos aztecas.

\title{
Modos de difundir la historia oficial
}

\section{La Historia en los medios audiovisuales mexicanos}

\begin{abstract}
"Partiendo de la evidencia de que tanto el qué como el cómo se recuerdan determinados acontecimientos no están desligados de los intereses de los diferentes grupos de poder del presente, debemos tener en cuenta que la actualización de la memoria sirve para afianzar las identidades establecidas desde los grupos de poder, legitimándose con la reinterpretación del pasado y su difusión masiva" (García Canclini, 2009).
\end{abstract}

Para el presente trabajo se ha rastreado y analizado, desde un punto de vista iconológico (Wittkower, Polo, Wittkower, \& Greco, 2006) la imagen del prócer Miguel Hidalgo y su paulatina conversión en Padre de la Patria y la distribución redundante de su imagen y del discurso oficial que le acompaña. Al encontrarnos enmarcados en el estudio de los productos culturales dentro de la era de la reproductibilidad, hemos estudiado la forma de representar durante la celebración del Bicentenario de la Independencia de México la figura de Hidalgo, y qué cambios se han dado a lo largo de estos doscientos años.

Utilizando las categorías de Calabrese (Calabrese, 1999), analizamos el producto novedoso dentro de estas celebraciones, el videojuego, cuya naturaleza responde a otro entorno diferente a los clásicos medios de masas, incluyendo la interactividad y cómo estas fortalezas se han aplicado a las características propias del videojuego.

\section{El medio audiovisual como agente de la historia}

El impacto que los medios audiovisuales provocaron en las sociedades occidentales del 
siglo XX se ha venido eclipsado en las últimas décadas con la irrupción de internet y la generalización de este. La popularización de los periféricos tecnológicos que con la llegada de la web 2.0 y los sistemas inalámbricos han dado lugar a un rico debate historiográfico, hoy tienen una presencia social que desborda la iconosfera (Gubern, 2007: 107-103) hasta límites jamás imaginados por Marc Ferro o Pierre Sorlín cuando escribieron los primeros textos sobre la relación entre cine e historia.

El cine, durante todo el siglo XX ganó enteros para posicionarse como gran divulgador histórico, así como para estar a merced de sus usos y abusos (Ferro, 2003), por parte de los diversos poderes. Certificado ya su uso como educador de masas a lo largo del siglo pasado (Donskoi, 1981) en el siglo XXI su gramática se ha extendido a otros medios como la televisión o los videojuegos con igual o superior capacidad como gran comunicador social. A este respecto se ha visto reflejado en múltiples ocasiones y las conmemoraciones históricas son una de ellas (Herrador Sánchez \& Morales Cevidanes, 2012). El cine ya se ve no sólo como fuente, o soporte de la historia, sino como un agente (Ferro, 1995: 97-137) que logra crear imaginarios de peso y gran difusión en el imaginario colectivo sobre determinado personaje o proceso histórico. Del mismo modo podemos considerar que todo medio que utilice su lenguaje, como es el caso de las series de televisión, la publicidad o los videojuegos responderían igualmente a este grupo de medios que se convierten en agentes de la historia siempre y cuando se encuentren dentro de un mercado de producción y distribución bajo una traza ideológica.

\section{Héroes de la patria: Hidalgo}

\section{Características del héroe latinoamericano moderno}

Los estudios sobre los mitos son innumerables; desde las disciplinas más variadas los mitos y los héroes han despertado el interés de la academia ya que su peso en el estudio de una cultura es vital. George Dumézil no había pueblos sin mitos o estos estarían muertos (Dumézil, 1970) y Levi-Strauss que "detrás de esa aparente irracionalidad debe subyacer un orden y un significado (Levy-Strauss, 2002: 33) Esa universalidad y ese significado que apuntan ambos maestros es lo que nos permite compartimentar el estudio del mito y del héroe en el nuevo panorama de lo masmediático a nivel geopolítico (Jameson, 1985).

El antropólogo Levi-Strauss pone a un mismo nivel lo mítico y lo científico como formas de un mismo modo de pensamiento, el humano. Sin embargo, esto no los iguala, lo que consigue Levy-Strauss es demostrar que sus funcionalidades y procesos de abstracción son diferentes (Lévi-Strauss, 2002: 40-44).

\section{El mito moderno. El héroe ilustrado}

Las transformaciones que la ilustración y sus consecuencias acarrearon al mundo no dejaron ajeno a sus influencias ningún aspecto de la cultura, la sociedad y la política de la época. Las bases de héroe y lo mitológico ya habían sido adoptadas por el cristianismo hasta hacerlos propios de lo sagrado y la santidad inaugura el subgénero biográfico de la hagiografía.

La modernidad no podía partir de otro lugar que sus bases, las fuertes estructuras religiosas y sus costumbres, ese concepto heroico que a veces tocaba lo sagrado.

La cascada de independencias que se producen a consecuencia de la de Estados Unidos y la Revolución Francesa hicieron tambalearse los cimientos de lo establecido para dar lugar a nuevas naciones y a un modo de pensamiento, el moderno, que va a dar lugar al concepto de Estado Nación actual. "Sin aura religiosa no hay veneración. A su modo, la nación es una entidad «mística» («La Patria es primero») y los héroes son los santos de la hora presente, cuyo sacrificio vuelve libres a los hombres y cuyo desinterés genera esa entrega valerosa 
a la nación que se da en llamar civismo. Durante el siglo XIX, el mecanismo es infalible: se combinan los santos propiamente dichos y el santoral republicano, las vírgenes y las heroínas, los beatos y los sabios. A la nueva tradición de los oficiantes en el altar de la Patria se le aplican los métodos de la hagiografía, que en la Edad Media ha visto concluir su crecimiento ilimitado:

"Dos conceptos se imponen, complementándose y dividiéndose el trabajo: la Historia y los héroes. En el siglo XIX, la Historia, nueva deidad de Iberoamérica, es, en cada país, la señal de la autonomía: «Si la Historia es nada más nuestra, ya somos algo. Tener Historia, así sea trágica, y sobre todo si es trágica, es señal de identidad»“(Monsiváis, 2000: 80).

\section{Del héroe de papel al massmediático}

\section{De la idea de héroe moderno a la carnalidad: El padre de la Patria}

Nos situaremos en el paradigma de la cultura visual, y rompiendo los cánones academicistas establecidos por la Historia del Arte y especialmente con la categoría de "obra maestra" para ver cualquier obra audiovisual como un objeto y sujeto de una época, haciéndonos entenderla, el objeto audiovisual como una construcción cultural y su devenir iconográfico como el de una época dominada por lo audiovisual.

Los estudios que relacionan historia o antropología y videojuego, dentro de los "game studios" (Wolf \& Perron, 2005) tienen diversas vertientes, aunque predominan dos, la ludología, que parte del clásico (Scolari et al., 2013) - que parte del clásico libro Homo ludens de Johan Huizinga y la narratología (Egenfeldt-Nielsen, Smith, \& Pajares Tosca, 2013). Debido a que los videojuegos que vamos a estudiar responden a la temática histórica y se encuentran enmarcados en un evento de carácter histórico lo trataremos desde ese punto de vista, narratológico y de contenido estético, viendo el videojuego como culmen de los objetos culturales complejos debido a su interactividad. Por lo que nos preguntaremos: ¿responde la relación de estos videojuegos con la capacidad audiovisual que ofrece el aprovechamiento de recursos de las diversas plataformas para videojuegos?

En el caso que nos ocupa encontramos una triple coincidencia para enmarcar el estudio, México es sujeto y objeto, y su ciudadanía emisor y receptor del producto cultural; y el protagonista el nombrado Padre de la Patria: Miguel Hidalgo y Costilla.

\section{Historia y medios audiovisuales}

Robert A Rosenstones, en History of film. Film on history, propone que es posible "escribir", hacer historia con el cine, la herencia literaria de la cinematografía no deja dudas. Finalmente son fuentes documentales las que nutren las narraciones audiovisuales, aunque es evidente que su principal interés, debido al propio medio, es la fuente plástica. De las fuentes o testimonios escritos que son consultados son de marcado carácter historicista y positivista, la biografía como fuente secundaria y la autobiografía como principal son lo que provoca que, en palabras de Ángel Luis Hueso "ofrecen un claro ejemplo de las preocupaciones icónicas que se desarrollan en estos años" (Hueso, 2001: 13).

\section{Historia visual de Miguel Hidalgo}

La contrucción del héroe moderno debe estar acompañada de los instrumentos que la sociedad de la época utiliza. Para estudiar la representación plástica de Miguel Hidalgo recurriremos a la propuesta de Rudolf Wittkower (Wittkower et al., 2006) haciendo una suerte de rastreo iconografico de carácter universal que nos lleve a las particularidades de México y que contemple todo tipo de representaciones y formatos, persiguiendo los atributos que se 
van repitiendo y con ello conformando la imagen del héroe moderno mexicano.

\section{El devenir de los atributos de la imagen patriótica de hidalgo}

La primera referencia que tenemos del aspecto físico de Hidalgo es de Lucas Alamán que lo describe como "de mediana estatura, cargado de espaldas, de color moreno y ojos verdes vivos, la cabeza algo caída sobre el pecho, bastante cano y calvo, como que pasaba ya de sesenta años, pero vigoroso, aunque no activo ni pronto en sus movimientos: de pocas palabras en el trato común, pero animado en la argumentación a estilo de colegio cuando entraba en el calor de alguna disputa. Poco aliñado en su traje, no usaba otro que el que acostumbraban entonces los curas de pueblos pequeños" (Alamán, 1985).

Durante los procesos de independencia y las consecuentes guerras internas nos encontramos con un vacío de imágenes de los representantes políticos que, paulatinamente, van a ir ocupando los antiguos espacios con retratos de los padres de la patria. Los nuevos héroes se representan en la pintura con la misma composición y pose que los mandatarios del Antigüo Régimen, pero con los nuevos atributos ilustrados y las insignias de la patria recién estrenada. La función legitimadora de los nuevos estados (Chust et al., 2003) ensalzaba en las representaciones el prestigio del personaje, en caso de estar vivo, o el crédito en caso de haber fallecido.

A mediados del siglo XIX, ya con los nuevos estados va a comenzar el proceso educativo social plagando las repúblicas de retratos y alegorías de la patria.

\section{El caso de Miguel Hidalgo}

A pesar de la corta trayectoria como líder insurgente de Miguel Hidalgo, su figura fue tomando peso desde su propio alzamiento; la propaganda que realizaban los insurgentes a su favor y la que lo demonizaba por parte de los realistas pusieron la primera piedra para el mito (Fabi, 2014). Pero fue con la industrialización porfiriana y la necesidad d celebrar el Centenario de la Independencia en un período con una política completamente enfocada en imitar y competir con los países europeos por la modernidad cuando la figura de Hidalgo toma fuerza massmediática.

Las bases van a ser pictóricas, los retratos, prácticamente idénticos de Joaquín Ramírez y Tiburcio Sánchez de la Barquera, pero fue su popularización por medio de los medios de reproducción y la generalización de estampas, anillos de puros y posteriormente el impacto como propaganda política del muralismo con los casos de José Clemente Orozco en el Palacio de Gobierno de Guadalajara y Juan O’Gorman en el Museo Nacional de Historia.

La imagen popular estalló a nivel de toda la Republica en los años setenta, cuando el ilustrador Jesús de la Helguera realiza para un público juvenil "La leyenda de los cromos", cuando la imagen de Hidalgo llega a la estandarización industrial.

\section{Características del héroe audiovisual}

La pintura decimonónica caló hondo, y el estándar cinematográfico de los héroes pasó de las artes plásticas a las cinematográficas casi sin mutación alguna. Tanto la pobreza técnica cinematográfica de finales de principios del siglo XIX, como la firme convicción, en un momento de moda historicista, los héroes de la patria debían contener una calma sobrehumana, propia de las miles de esculturas de bronce o mármol que germinaron en las ciudades.

La representación se realizaba con cierto abuso de los primeros planos de los personajes principales, en nuestro caso Hidalgo, despachos con los atributos propios del pensador, la Virgen de Guadalupe como su estandarte y reafirmación católica, el traje de sacerdote.

Esto nos lleva a reafirmar una de las características que el semiólogo Omar Calabrese apuntó sobre la era neobarroca que vivimos, la repetición en un modo de variacion indis- 
troalozada, organizada, un policentrismo que sitúa al personaje en el "exceso" con respecto a la sociedad que lo consumo en todos los focos de atención; en el Bicentenario se vivirá un ritmo frenético de representaciones de Miguel Hidalgo que nos muestra la irregularidad regulada que aventuraba el semiólogo italiano.

Todas estas variantes -publicidad en los más diversos productos, cuadernos, cromos, pegatinas, lápices, ropa... reafirman la postura del italiano con respecto al consumo icónico como "elección de vida"(Calabrese, 1999), la adaptación del héroe atendiendo a los mínimos cambios para que el discurso no varíe, permanezca, ya la mínima crítica determina la lógica de la seriación, de las constantes citas de los que se va nutriendo cada realizador de la imágenes de Miguel Hidalgo.

\section{Hidalgo en el Bicentenario}

\section{Recorrido mass mediático a la imagen de Miguel Hidalgo}

Si bien en México la lectura no entra dentro de los grandes consumos culturales, la exposición en escaparates y kioscos de prensa de libros y revistas conmemorativas, el reparto a domicilio de volúmenes ilustrados institucionales o los carteles de las exposiciones y eventos invadieron las ciudades, por lo que, aun no siendo ávidos lectores, las portadas de dichos productos, en los cuales los editores prestan gran parte de la atención del producto, bombardearon a la población.

En estas portadas podemos observar el nulo cambio de perspectiva con respecto a la representación icónica de la independencia, pues será Miguel Hidalgo y, en segundo término José María Morelos o, en una posición considerablemente marginal Josefa Ortiz de Domínguez "La Corregidora", lo que evidencia, de nuevo la marginalidad de la mujer en los protagonismos políticos e históricos, así que pasen doscientos años.

Otro de los grandes olvidados, y que podemos observar rápidamente al ver las portadas de las publicaciones es el pueblo, y sobre todo el indio, anulado como actor social tanto por la historia oficial como por los diversos festejos que desde 1910 se han realizado a consecuencia de la Independencia y los diferentes eventos conmemorativos de personajes particulares. El pueblo ha sido obviado, olvidado, de la representación icónica de la independencia perviviendo la postura de ensalzamiento de héroes.

\section{Cómic}

Durante 2010 se publicaron numerosos comic relacionados con el evento; entre los más vendidos y esperados nos encontramos con tres de diferente corte. El más apegado a la enseñanza de la historia y de naturaleza estética más realista está el editado por el Colegio de México, una adaptación gráfica del texto original de Josefina Zoraida Vázquez por Francisco de la Mora y Rodrigo Santos, ilustrado por Jorge Aviña.

El siguiente es de un clásico del comic mexicano, el afamado divulgador Ríus, de título "Ni Independencia ni Revolución" más personal y crítico, utilizando collage y sus clásicas citas ara la composición de un texto crítico con el evento y la historia de México.

Los problemas historiográficos que suscitan la historia oficial se ve reflejado en el comic de Trino, de dibujo más caricaturesco y humorístico "Historias desconocidas de la Independencia y la Revolución" hace una reflexión crítica sobre la continuidad de los problemas del país. Tanto en el Comex como Trino ponen a Hidalgo en la portada.

\section{Cine}

\section{Hidalgo como protagonista cinematográfico}

En el cine la primera representación es de 1907, en la película muda El grito de Dolores 
o La Independencia de México, dirigida y protagonizada por el aristócrata porfirista Felipe de Jesús Haro, del que se desconoce su lugar y fecha de nacimiento y defunción (Cuik, 2009: 390).

En este subgénero, el movimiento de la película depende por completo de los actores, pues la cámara está invariablemente fija, mientras que la actuación es teatral, como resulta lógico en una película de esos tiempos. Generalmente Hidalgo ocupa el centro de la imagen o guía el movimiento de los demás, y no hay historias paralelas que distraigan del núcleo de la narración. Este estilo, sin mayores variantes ni riesgos, buscaba sobre todo ilustrar de manera clara la historia conocida, para que amplios sectores de público pudiera comprenderla e identificarse con ella. (Miquel, 2010: 13-14).

Desgraciadamente, la siguiente película que toca el asunto, 1810 o Los libertadores de México (Carlos Martínez Arredondo, 1916) se encuentra extraviada, lo único que nos queda es lo que recuerda su fotógrafo, Martínez de Arredondo (Miquel, 2010: 21), que nos aclara el carácter folletinesco del film, donde para representar la lucha, se recurre a una historia de amor. En este film, Carmen es una bella mexicana enamorada del ranchero Nicolás, pero es asediada por un pérfido intendente español interpretado por José Viñas. Hidalgo (Alfredo Valera, se desconoce lugar y fecha de nacimiento y defunción) aparece aquí como padrino de los novios, los cuales son encarcelados por las influencias del intendente y rescatados por los insurgentes.

Con la llegada del sonido comienzan las peripecias cinematográfico-históricas de Miguel Contreras Torres con ¡Viva México! (Alma insurgente), donde Hidalgo es representado por Paco Martínez (Valencia, España, 1871-Ciudad de México, 1956).

A diferencia de 1810 o los libertadores de México el bonachón y bondadoso Hidalgo que ser representa en esta película no carga contra los españoles, sino que se muestra conciliador, aunque amante de Voltaire y de La Marsellesa que reconoce como un "canto de libertad". Miguel Hidalgo es interpretado por Julio Villarreal (Lérida, España, 1885-Ciudad de México, 1958), que representa a un personaje "serio, solemne, astuto y un poco antipático" (Miquel, 2010:20) al que apodan El Zorro desde su estancia en el Colegio de San Nicolás, según avisa Allende a Aldama. Su representación en esta película evidencia que el autor tomó como referencia las imágenes populares de Hidalgo que durante estos años proliferaban por México.

En La virgen que forjó una patria (Contreras Torres, 1942), Miguel Hidalgo es interpretado por Julio Villarreal (Lérida, España, 1885-Ciudad de México, 1958). En esta película, embutida en un flash back, Hidalgo considera que el verdadero inicio de la historia en México fue la aparición de la Virgen de Guadalupe:

"La virgen de los mexicanos [...] hoy por hoy no hay mejor símbolo de la nacionalidad que tratamos de forjar que la imagen morena de la Guadalupana [...] criollos, mestizos e indios, es decir, todos los que vamos a lanzarnos contra los europeos que nos gobiernan. [...] Tres siglos alrededor suyo se ha venido forjando esta patria que nosotros pretendemos ahora construir."

Ángel Miquel nos aclara perfectamente la intención de esta cinta:

"se puso en boca de Hidalgo un sentimiento identitario americano que, a lo largo de tres siglos de Colonia, habría ligado a quienes por distintos motivos se oponían al dominio español. Esa oposición nació, según dice Hidalgo a Allende, de los primeros indígenas sojuzgados por los encomenderos, pero se fue generalizando para incluir también a criollos y mestizos, desplazados en todos sentidos por los peninsulares. El vínculo entre indígenas, mestizos y criollos, afirma Hidalgo, es la virgen de Guadalupe, 'un símbolo de igualdad 
y de redención, una bandera que irá fraguando una nacionalidad y forjando una patria'. Puesto que su imagen sintetiza desde el punto de vista político la aspiración común de independencia del europeo, el cura convence a Allende que deben adoptarla como símbolo del movimiento para 'libertar a los americanos de estas tierras de Anáhuac de los europeos de Castilla, de Andalucía o de cualquier otra región de Europa que pretenda alguna vez someternos bajo el pretexto de que tienen blanca la piel'. La identidad mexicana habría surgido, pues, según Hidalgo, por oposición a un enemigo común: los españoles" (Miquel, 2010:19).

A pesar de ello, intenta librar la honorabilidad de "algunos" españoles que defienden a los indios, como fray Juan de Zumárraga, fray Martín o Vasco de Quiroga. La película, en general, se caracteriza por su ritmo lento, heredero de la concepción pétrea y broncínea de la Historia, aunque Emilio García Riera (García Riera, 1999: 186) lo interpreta como metáfora del estatismo derechista y religioso del director.

\section{Hidalgo en el cine de 2010}

La película icono sobre la independencia en 2010 es Hidalgo. La historia jamás contada (Antonio Serrano Argüelles, 2010) donde se representa a un Miguel Hidalgo humano, dicharachero, mujeriego y enfrentado al poder eclesiástico. Si bien se trata de una historia considerablemente maquillada, cuenta con la representación de episodios apartados de la idea hagiográfica de Miguel Hidalgo representada hasta la actualidad.

El diseño de producción a cargo Brigitte Broch, es excelente, con un cuidado vestuario dirigido por Leticia Palacios que hace creíble a los personajes (Sánchez Quiroz, J. Pérez, 2010: 32). Para Betancourt, crítico del semanario Proceso, este Hidalgo que encarna Demián Bichir supo asimilar el impacto de sucesos internacionales tan importantes como la dramática expulsión de los jesuitas, orden de gente pensante, en su momento. El teatro aparece en la vida del joven Hidalgo como un leitmotiv; el héroe de Serrano muestra más vocación de hombre de teatro que de militar revolucionario, aunque es probable que para el director de Sexo, pudor y lágrimas, teatro y liberación sean sinónimos. Quizá por esto, la mayor parte de la cinta transcurre y gira en torno a la puesta del Tartufo, la pieza en la que Moliere critica implacablemente la mojigatería y su complicidad con el poder. Pese a los traspiés de un guión que no termina por encontrar un habla coherente, entre lo castizo y el mexicanismo, antiguo y moderno, Hidalgo, la historia jamás contada abre un camino a la construcción de un héroe auténtico, más a la altura del arte"(Betancourt, 2010: 70). Un análisis más profundo y detallado del film esconde una contradicción entre el discurso narrativo y el visual; si bien durante toda la película se reivindica la libertad del indígena, éstos son representados como individuos pasivos de su historia, como atrezzo.

Una visión mucho más institucional y con intención de servir como medio educativo es la película Héroes verdaderos, de la productora White Knight Creative Production encargada a Carlos Kuri, la cual ha tenido duras críticas por su enfoque racista (Woodside, 2012), donde se retoma al personaje bonachón e inspirado en las imágenes más pop. Plagada de personajes, maniquea y desordenada, esta película realizada para el público infantil cae en todos los tópicos habidos y por haber de la figura de Hidalgo, estéticamente representado como un personaje Disney; en contraposición con la imagen de Morelos, más influenciada por la estética manga japonesa.

\section{Hidalgo en la ficción televisiva}

Sin duda uno de los consumos culturales de mayor impacto a nivel mundial es la televisión, y México destaca, fundamentalmente con Televisa, como uno de los mayores pro- 
ductores y exportadores de telenovelas del mundo. Como era de esperar no se podía perder la ocasión de que la mastodóntica Televisa hiciese una serie con una superproducción que acabó llamándose Gritos de muerte y libertad que, si bien tendía a apegarse a los hechos históricos, adolecía de un acartonamiento heredado de los "héroes de bronce" encabezado por el actor Alejandro Tommasi. Esta serie de trece capítulos narra desde el levantamiento de Miguel Hidalgo hasta el nacimiento de la República y se va enlazando su narración con la presentación de los "hechos" de los diversos héroes de la patria mexicana finalizando con Guadalupe Victoria.

Por su parte, la cadena cultural Once TV México realiza Los Minondo bajo la dirección de Carlos Bolado, Emilio Maillé y Charlie Gore. Esta serie se desmarca del uso constante de los héroes patrios para centrarse maniqueamente en la narración de la Independencia y la Revolución a partir de dos tramas, la de la familia Minondo que llega de la península huyendo de un Conde enamorado de Cayetana, su prometida, a la Nueva España y siembra de horrores las tierras que pisa, y otra historia se inicia cuando Manuel Minondo llega a la Nueva España y es curado por la hermosa Eduviges en Xochimilco, de la que se enamora y con la que tiene un hijo, pero que abandona al enterarse de la llegada de Cayetana y conformar una familia legítima y tradicional. Por lo que, si bien la serie se aparta de los "héroes de bronce", cae en el tópico del español/criollo malvado frente al indígena bueno que da lugar a un vengativo mestizo, continuando con los tintes de la "historia oficial". Reredactar.

José Carlos Rodríguez interpreta al padre de la patria en el tercer capítulo, precisamente titulado "El cura Hidalgo", continuando las mismas características estéticas de hace dos siglos pero incluyendo en su discurso la culpa por la matanza de la alhóndiga de las Granaditas; episodio que ha estado ausente de estas narraciones.

\section{Hidalgo en los videojuegos}

\section{Los videojuegos en México}

Dentro del vasto mercado latinoamericano, la industria del videojuego en México es de las más significativas. Su valor es de miles de millones de pesos y su crecimiento exponencial; sobre todo tras la aparición de las nuevas plataformas portátiles para su consumo, como los teléfonos móviles o celulares en la vida diaria de la población. Según apuntaba recientemente la revista Forbes, el mercado del videojuego en México al cierre del año 2016 se cifraba en 22.852 millones de pesos; un crecimiento del 13,3\% en seis años, según un análisis de The Competitive Inteligence Unit ${ }^{2} \mathrm{El}$ año de la celebración del Bicentenario fue para el videojuego un año de gran expectación con lanzamientos de la talla de God of War III (Sony, 2010). Asassin's Creed: Bortherhood (Ubisoft, 2010), Medal of honor (Electronic Arts, 2010) o Dante's Inferno (Electronic Arts, 2010). Que los videojuegos que se realizaran para el evento desde la industria con apoyo estatal mexicana intentaran introducir su producto en ese mercado resultaría poco sensato o pretencioso para las posibilidades y fines de las instituciones. Tampoco es la intención de estos videojuegos, que sería la "enseñanza de la historia" entraría dentro de las complicadas narrativas de estos videojuegos, por lo que se optó por las plataformas móviles, aunque privilegiando la plataforma de Apple. En este trabajo centramos la atención en los videojuegos puestos a disposición pública, de forma gratuita apoyados por el Estado. Para su análisis nos enfocamos en una perspectiva, ya muy extendida, de la educación histórica a través de los videojuegos, ya que la vertiente de didáctica de la historia ha sido la más subrayada tanto por el Estado como por los realizadores. Los videojuegos a tratar son tres: Memorias de una Nación (Ikoriko, 2010), Bicentenario 2010: los héroes de México (Neggi, 2010) e Independencia de México. La lucha por la libertad (Barro Negro, 2010).

2 www.forbes.com.mx/mercado-de-videojuegos-en-mexico-vale-mas-de-22800-mdp/\#gs.o31TS8k (Última consulta 16 de noviembre de 2016) 


\section{Videojuegos y enseñanza de la historia}

La preocupación pedagógica acerca del videojuego se inicia antes que los propios Game Studies (Findling, 2008) ; la aportación de nuevas tecnologías siempre genera suspicacias, y el videojuego, aparecido en plena Guerra Fría no podía ser menos. La literatura en pro y en contra de los "marcianos" o las polémicas sobre violencia o adicción quedaron superadas en parte para estudiar de forma más pormenorizada y menos prejuiciosa este universo. Ya en 1976 Topolski, en su clásico Methodolohy of History (Varsovia, Polish Scientifics Publisher) apuntaba la necesidad de la ubicación espacio-temporal del hecho histórico, siendo esto "fundamental para dotar a su conocimiento de un contexto y, por ende a el fin último, una proyección en futuros procesos productivos (Topolski, 1976)Desde el punto de vista de la pedagogía de la historia se han hecho numerosos trabajos (Cuenca, Martín, \& Estepa, 2011), algunas como resultade de ambiciosos proyectos de investigación multidisciplinar y experimental como el dirigido por Juan Francisco Jiménez Alcázar específicamente dirigido al estudio del medievo (Juan Francisco Jiménez Alcázar, 2009) Y lo que podemos concluir a este respecto es claro, que el videojuego, por su naturaleza e interactividad, facilita la adquisición de conocimiento, siendo su gran ventaja la enseñanza de procesos históricos complejos, ya que es prioritaria para la enseñanza la "ubicación de los hechos en el espacio y en el tiempo, y su posterior secuenciacion dotada de causas y consecuencias" (Gálvaez de la Cuesta, 2006: 2-3) Como expone Gros "los juegos de ordenador poseen un gran valor educativo por las siguientes razones:

- Constituyen un material que por si mismo resulta muy motivador para los niños.

- Favorecen el trabajo de aspectos procedimentales tales como habilidades viso-motoras, toma de decisiones, resolución de problemas y habilidades metacognitivas. En este punto vemos como el niño continuamente analiza su actuación anterior para decidir en el paso siguiente, establecer cuál es la estrategia más adecua? da para poder resolver las diferentes situaciones de juego.

- Los juegos son programas muy flexibles dado que se pueden utilizar para desarrollar contenidos de un área concreta o bien como eje transversal en temas difíciles de tratar directamente a partir de un área concreta.

- Proporcionan elementos para el desarrollo de la autoestima.

- Es un material informático al alcance de todos, en la escuela y en casa.

- La utilización de los juegos de ordenador puede ser de gran ayuda no obstante no debemos pensar que podemos coger un juego cualquiera, hacer jugar a los niños y observar los resultados, como todas las actividades en la escuela debe estar convenientemente planificadas en el proyecto curricular." (Gros, 1998: 91).

Partiendo de aquí veremos qué proporcionan a los consumidores los videojuegos realizados como conmemoración del bicentenario de México.

\section{Memorias de una Nación (Ikoriko, 2010)}

Memorias de una Nación es un paquete informático dividido en tres apartados; una primera sección nos encontramos con la aplicación "Museo Bicentenario Virtual”, por lo que directamente los autores lo sacan de la categoría de videojuego. Continúa el paquete con el videojuego "Sombras heroicas", diseñado para niños de 3 a 5 años, en el que hay que relacionar ocho personajes de la Independencia y la Revolución de México con sus sombras; y se completa el conjunto con un juego tipo trivial de conocimiento de hechos a conmemorar 


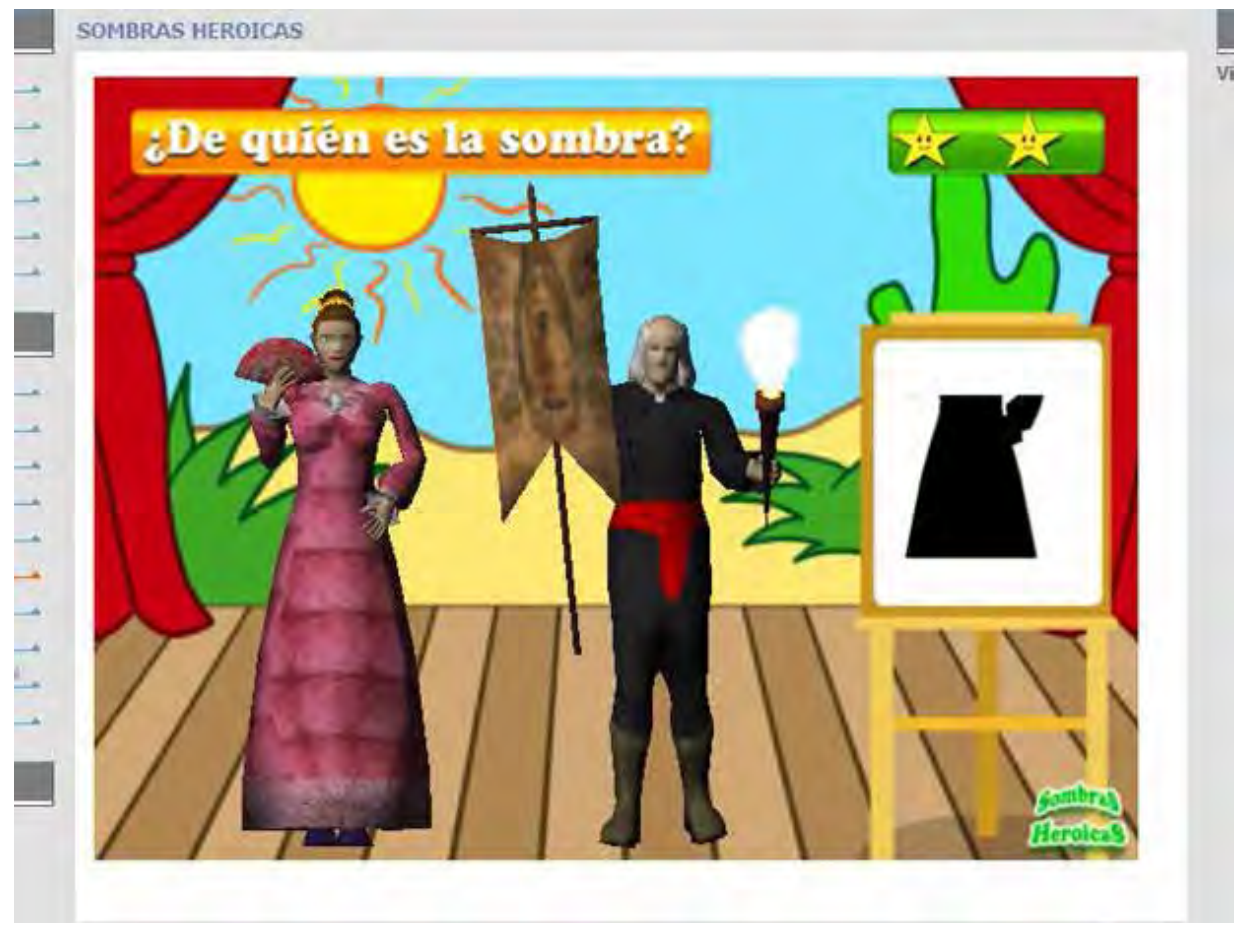

Ilustración 1 Captura de pantalla de "Sombras heroicas".

“Caudillos de la Patria”. Este paquete estuvo desarrollado por Alex Lerma (Ikoriko) y asesorado por el historiador David Guerrero Flores (Director de difusión INEHRM). Este paquete de entretenimiento fue apoyado desde instancias gubernamentales por la secretaría de Gobierno y el fondo PYME junto a la pequeña empresa de videojuegos Ikoriko, que resultó ganadora del concurso "Juego de Talento" organizado por la Comisión del Bicentenario con el fin de incentivar la creación de videojuegos de temática histórica. "Sombras heróicas" la primera parte lúdico-didáctica, consta de una pantalla bidimensional en la que aparecen dos personajes de la Independencia yo Revolución y hay que compararlo con un segmento en sombra que se muestra en una pizarra. Aquí tropezamos con Calabrese -Detalle y Fragmento- para luego, en caso de acertar, ser premiado con un cartel de “¡Felicidades!” coronado por un medallón plateado donde se encuentra esgrafiado el Monumento a la Revolución de la Ciudad de México. Al igual que la siguiente parte lúdica, el trivial "Caudillos de la Patria" es difícilmente analizable y catalogable a la luz de los parámetros del videojuego coetáneo a su producción.

Si bien es cierto que las plataformas actuales para dispositivos portátiles han simplificado considerablemente el gameplay de los videojuegos expuestos al consumidor con el fin de acaparar todo el mercado de los muy numerosos usuarios de smartphone; una comparativa de sombras o un trivial resultan más recursos pedagógicos digitalizados que no cuentan con las posibilidades que da el mundo del videojuego para la exposición de hechos históricos. De hecho, no responde a ninguna de las ventajas que mencionan los expertos anteriormente citados sobre las bondades de aprender historia aprovechando la interactividad y la recompensa inmediata del videojuego. Memorias de una nación ya fue analizado desde un punto de vista pedagógico (Ramírez Zaragoza, 2012) y si bien durante la exposición se critica a los autores del videojuego su simplicidad, en las conclusiones procuran salvarlo ya que, en general, es una novedad para México y por la adecuación de la edad según las teorías de Jean Piaget. Es necesario discutir este punto, pues si la finalidad del juego es el conocimien- 
to de los hechos en su contexto, éste no cumple en absoluto con ese mínimo requisito para incluirlo dentro de la categoría de videojuego histórico.

\section{Bicentenario 2010: Los héroes de México (Neggi Studios, 2010)}

Este videojuego se lanzó en dos momentos clave del 2010, el 16 de septiembre, y para la plataforma iOS la parte dedicada al Bicentenario de la Independencia, y el 20 de noviembre el dedicado al Centenario de la Revolución. Según sus creadores este videojuego está diseñado para que los "niños y jóvenes jueguen a ser los héroes de ayer y entiendan el valor de ser los ciudadanos del mañana".

Este paquete informático salió de la conexión entre Gobierno (Fondo Profort de la Secretaría de Economía), la Universidad (Incubadora de Empresas del Tecnológico de Monterrey) y un pequeño estudio (Neggi). Su director ejecutivo fue Germán Vázquez, y el director general del proyecto Ivan Ramirez; la música estuvo a cargo del artista local Ezekiel. El videojuego abarca los dos hechos de la celebración. Nos centraremos en los de la Independencia. Según sus autores se trata de un videojuego de "estrategia en tiempo real que pone al jugador en control de las fuerzas insurgentes en batallas clave de la Historia de México. Si bien sus creadores lo sitúan dentro de los videojuegos de esta categoría, consideramos que es un error ya que esto nos puede llevar a pensar que se trata de un videojuego tipo Age of empires (Ensemble Studios, 1997) o Rise of Nation (Big Huge Games, 2003), pero realmente se trata de un tipo de "tower defense" en el que el gameplay se repite y sólo cambian los escenarios. Todo se sitúa en un cuadro sin ningún movimiento posible que está centrado en un edificio emblemático y el jugador cuenta con tres tipos de insurgentes y otros tres tipos de defensas terrestres en puntos ya predefinidos por el juego y que disparan o entorpecen la avanzada de las fuerzas realistas por recuperar el sitio. Los escenarios son tres: la Alhón-

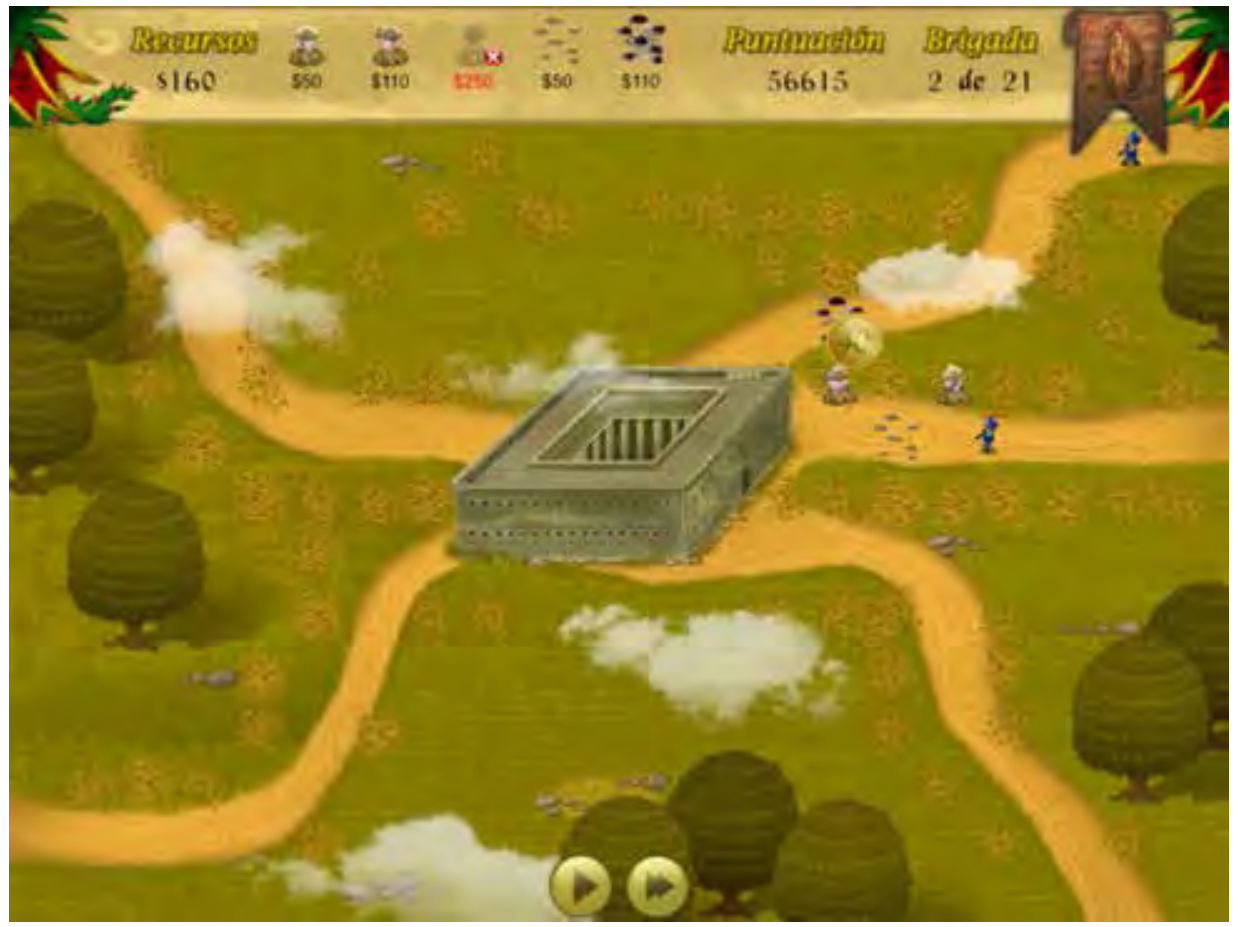

Ilustración 2 Captura de pantalla de"Los héroes de México» en la defensa de la Alhóndiga de las Granaditas. 


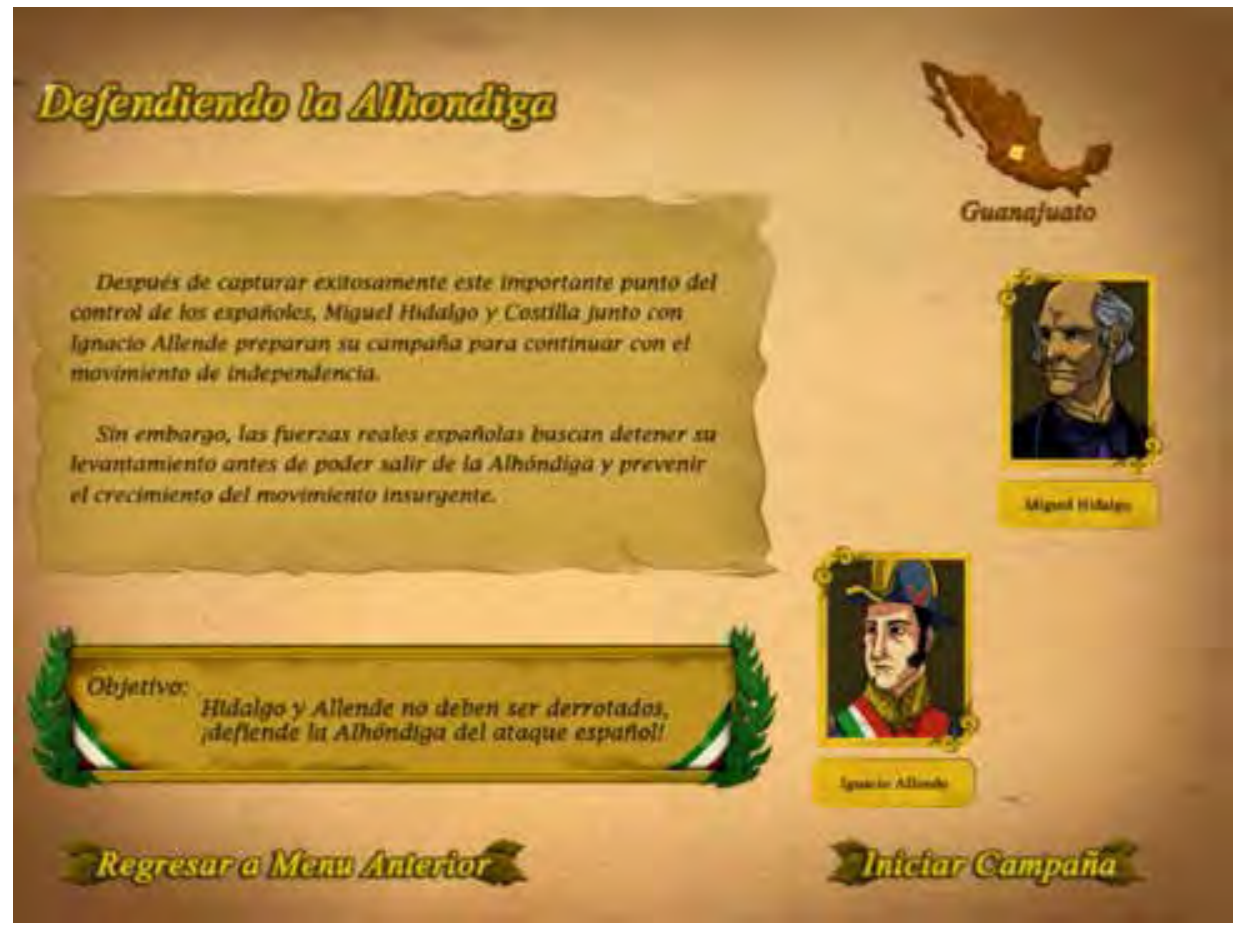

Ilustración 3 Captura de pantalla introductoria a la defensa de la Alhóndiga de las Granaditas.

diga de las Granaditas (1810), donde el jugador tiene que defender la posición tomada por Hidalgo y Allende; el Río de Soto La Marina (1817) donde Francisco Javier Mina defiende el puesto y el Sitio de Cuautla (1812) protagonizado por José María Morelos.

El videojuego fue aprobado por el Consejo del Software de Nuevo León, pero sigue presentando una propuesta escueta, aunque más cercana a la experiencia de videojuego, aun así los propósitos de contextualización y entendimiento de los hechos quedan anulados. Se trata de plasmación de hechos completamente aislados de la historia de México y Universal, exceptuando un breve texto carente de exposición de hechos históricos (económicos, sociales, ideológicos...) y el retrato de los héroes Hidalgo y Allende asentados por la Secretaría de Educación Pública y la historia oficial.

\section{Héroes del Bicentenario (Barro Negro, 2010)}

Este viudeojuego, indicado para niños mayores de 4 años representa de forma inigualable la repetición de Calabrese. Encontramos tres juegos de mesa adaptados a la tableta. Un "Juego de Conocimiento" completamente descontextualizado, por lo que inútil para las pretensiones educativas. Preguntas aisladas como "¿Quién es el autor de Sentimientos de una nación? A) José María Morelos; B) Vicente Guerrero; C) Miguel Hidalgo" deben de servir para que el niño se aproxime al evento histórico. Un segundo juego es memorístico, destapar pares de cartas hasta encontrar las parejas de héroes, con lo que alimenta la iconosfera establecida por la Historia Oficial. El tercer juego "Ilumina" consta de una plantilla donde los niños podrán colorear a los héroes de la Patria (Hidalgo, Morelos...) con una paleta de colores prefijada para evitar errores cromáticos. Aquí encontramos en las autopresentaciones de los héroes un discurso como el siguiente "Hola, soy Miguel Hidalgo, me llaman el Padre de la Patria, también me conocen como el cura Hidalgo. Fui iniciador de la lucha de independencia de México. Estudié filosofía y teología, aprendía a hablar francés y varias lenguas indígenas como otomí, purépecha y náhuatl. Tras 400 años de ocupación española 
en México, el corregidor de Querétaro, Miguel Domínguez, y su esposa Doña Josefina Ortiz de Domínguez junto con otros militares, organizaron un plan para liberar a México de los españoles. Como sacerdote, mucha gente me escuchaba y me seguía, ese fue el motivo principal para que me invitaron a participar en la lucha y acepté gustoso. El movimiento se estaba preparado para octubre, pero a principios de septiembre, virrey, Francisco Javier Venegas, llegó a México y ordenó una búsqueda de aquellos que estaban en contra de la corona español. Fue por eso que la madrugada del 16 de septiembre don Ignacio Allende llegó a mi casa, en Dolores y decidimos lanzarnos a la lucha armada antes de que los españoles nos descubrieran. Convoqué a misa y con la Virgen de Guadalupe como nuestro estandarte invité al pueblo a luchar por nuestra independencia acompañado de otros valientes líderes. Fui capturado en 1811 llevado a prisión y fusilado el 30 de julio, pero sigo vivo en todos los niños y niñas mexicanos por lograr que nuestro México se convirtiera en un país libre e independiente". Si bien intenta contextualizar sólo responde a los territorios comunes del mito, a parte de errar poniendo una bandera constitucional española como si fuese la del siglo XIX, o 400 años de ocupación en lugar de 300 (1521-1921). Este texto se podría equiparar en su adjetivación a clásicos de la historia oficial como "México a través de los siglos", donde se describe a Hidalgo como "La idea de la Independencia había encamado al fin en un hombre altivo y osado que durante muchos años meditó en el silencio y en el retiro la gigantesca obra de emancipar a la colonia. Hidalgo concentra las aspiraciones justísimas de la inmensa mayoría de los mexicanos; con pobre acopio de elementos materiales, pero con caudal inmenso de esperanzas; con ciega fe en el resultado final de su alta empresa; con la abnegación que es dote de los fundadores de naciones, resuélvese a apresurar la hora suprema urgido por el descubrimiento de su grandioso proyecto, y cuando sabe que la orden de su prisión ha sido expedida por las autoridades españolas, el cura de Dolores aparece con toda la grandeza de los héroes antiguos al asomar la aurora del 16 de septiembre de 1810 . ¿Qué grupo es ese que en atrio de una humilde iglesia levanta hasta las nubes entusiasta clamoreo? ¿Quién es el jefe de esa muchedumbre que por momentos crece y se agiganta, y que al expirar ese mismo día era ya numerosísimo ejército que entraba en San Miguel el Grande

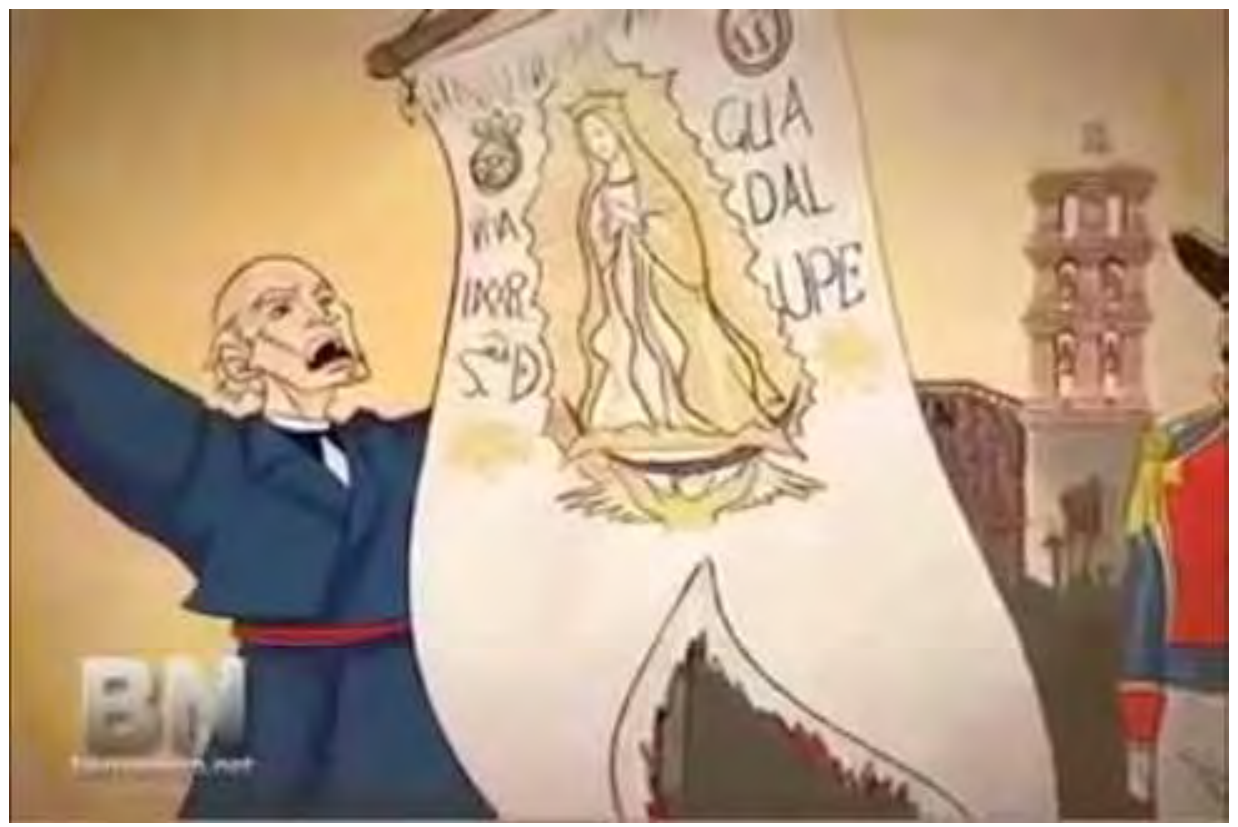

Ilustración 4 Captura del videojuego Héroes del Bicentenario. 
al compás de sus cantos marciales? Ese grupo es el núcleo de un pueblo que se lanza a la conquista de sus más sagrados derechos; ese caudillo es el varón ilustre y fuerte que acepta el martirio desde el instante en que su voz augusta convoca a sus hermanos para alcanzar la independencia. Por eso México le llama el Padre de la patria”, publicado en México por Vicente Riva Palacio en 1884. A pesar del paso del tiempo, la retórica y la adjetivación casi queda intacta en ambos discursos, lo que nos descubre esa reiteración de discurso la nula intención educativa del producto, que torna siendo finalmente dogmática y alentadora de la regeneración de Héroes estandarizados iconográfica y discursivamente.

\section{Conclusión}

Partiendo de un análisis iconográfico de los modos de representar la independencia durante los productos culturales que se desarrollaron para celebrar el Bicentenario de la independencia de México nos percatamos de que la imagen que inunda el mundo audiovisual en el México de 2010 es la del prócer Miguel Hidalgo. Tras usar la metodología iconológica de Rudolf Wittkower podemos encontrar un punto de conexión entre las teorías de cine como agente de Marc Ferro y las de repetición y consumo de Calabresse.

Esta multiplicidad de lenguajes y de puntos de vista analizados en su profundidad, delata que la huella de la llamada "historia oficial" es profunda, y que en escasas ocasiones los medios de masas tienen posibilidad de escaparse de ella para plantear posturas más científica y modernas desde el punto de vista histórico y antropológico - con sus mil matices y visiones sobre la sociedad, la cultura, la política o las artes- una nueva visión de su historia que le hagan partícipe y no público pasivo ante los hechos de los héroes creados.

El caso de los videojuegos evidencia que el gusto de la época que plantea Calabrese es simple, reiterativo, con mensajes rápidos, descontextualizados e historicistas; un modelo decimonónico en instrumentos posmodernos. Nuestra postura defiende que no es suficiente con el uso de un dispositivo nuevo, sin contar con el contenido y las posibilidades del mismo, para evaluar positivamente un producto cultural dedicado a la población. Es relevante pues, aun teniendo como elemento intrínseco la interactividad, como los videojuegos realizados para el fin de celebrar el Bicentenario desprecian sus posibilidades educacionales con el fin de continuar reafirmando la "historia oficial" manteniendo un status quo ideológico que nos conecta por un período de doscientos años al yugo del positivismo y la ideología dominante asociada a los grupos de poder como configuradores de la identidad nacional.

\section{Bibliografía}

Alamán, L. (1985). Historia de Méjico. Desde los primeros movimientos que prepararon su Independencia en el año de 1808 hasta la época presente (Edición facsimilar de la de 1849). México: Fondo de Cultura Económica.

Benjamin, W., Weikert, A. E., \& Echeverría, B. (2003). La obra de arte en la época de su reproductibilidad técnica. México: Ítaca.

Betancourt, J. (2010). Hidalgo. La historia jamás contada. Proceso, (1770).

Calabrese, O. (1999). La era neobarroca. Catedra. http://doi.org/ISBN 8437608635

Cardoso Vargas, H. A. (2006). La mexicanidad en el libro de texto gratuito. Odiseo. Revista Electrónica de Pedagogía, 16(6), 26. Retrieved from http://www.odiseo.com. $\mathrm{mx} / 2006 / 01 /$ cardoso-mexicanidad.htm

Chust, M., Mínguez, V., Damas, G. C., Chust, M., Connaughton, B. F., Fowler, W., ... Zarate, V. (2003). La Construcción Del Héroe En España Y México ( 1789-1847 ).

Cuenca, J. M., Martín, M., \& Estepa, J. (2011). Historia y videojuegos. Iber, 69, 1-10.

Cuik, P. (2009). Diccionario de directores del cine mexicano. Tomo I. México: Instituto Mexicano de Cinematografía / Dirección General de Publicaciones.

Donskoi, M. (1981). Lenin y el cine. Madrid: Fundamentos.

Dumézil, G. (1970). The Destiny of the Kings. Chicago: The University of Chicago Press. 
Eco, U. (1999). Apocalípticos e integrados. Palabra en el tiempo. Ensayo (Vol. 39).

Egenfeldt-Nielsen, S., Smith, J. H., \& Pajares Tosca, S. (2013). Understanding Video Games. Routledge.

Fabi, O. (2014). La primera construcción mítica en torno a Miguel Hidalgo *. Revista de El Colegio de San Luis, (8), 160-190.

Ferro, M. (1995). Historia contemporánea y cine. Barcelona: Ariel.

Ferro, M. (2003). The use and abuse of history (Routledge). Nueva York: Routledge.

Findling, J. (2008). Integration of Game-Based Learning into a Social Studies Curriculum Model to Improve Student Performance in the Ohio Social Studies Standards, (August). Retrieved from https://etd.ohiolink.edu/!etd.send_file?accession=bgsu $1218489507 \&$ disposition=attachment

Florescano, E. (1989). Teresa de Mier y Bustamante. Fundación del nacionalismo histórico. Nexos.

Gálvaez de la Cuesta, M. del C. (2006). Aplicaciones de los videojuegos de contenido histórico en el aula. Icono14, 7, 217-230.

García Canclini, N. (2009). Culturas híbridas. México: Debolsillo.

García Riera, E. (1999). Breve historia del cine mexicano. Primer siglo (1897-1997). México: Conaculta, Imcine, Canal 22, Universidad de Guadalajara, Ediciones MAPA.

González, L. (2006). La historia académica y el rezongo del público. Istor, VIII(29), 98-99.

Gros, B. (1998). Jugando con videojuegos : educación y entretenim iento. Bilbao: Desclée De Brouwer.

Gubern, R. (2007). Del bisonte a la realidad virtual. La escena y el laberinto. Barcelona: Anagrama.

Herrador Sánchez, J. Á., \& Morales Cevidanes, M. Á. (2012). La Constitución de 1812 y el Bicentenario de la Independencia de Iberoamérica en diferentes soportes icónicos. México: Upo Innoba.

Hueso, Á. L. (2001). La biografía como modelos histórico-cinematográfico. Historia Contemporánea, 1(22), 97-115.

Humboldt, A. D. (1975). Ensayo Político sobre el reino de la nueva España. México: Porrúa.

Jameson, F. (1985). La estética geopolítica. Cine y espacio en el sistema mundial. Barcelona: Paidos.

Juan Francisco Jiménez Alcázar. (2009). Videojuegos y Edad Media. Imago Temporis, 3, 551-587.

Lévi-Strauss, C. (2002). Mito y Significado. Madrid: Alianza.

Miquel, Á. (2010). La ficción de la historia. El siglo XIX en el cine mexicano. México: Cineteca Nacional.

Monsiváis, C. (2000). Aires de familia. Cultura y sociedad de América. Barcelona: Anagrama.

RAmírez Zaragoza, J. A. (2012). Evaluación Del Videojuego Memorias De Una Nación Para Su Aplicación En La Enseñanza De Historia De México. Retrieved from http://congreso.pucp.edu.pe/alaic2014/grupos-tematicos/gt-4-comunicacion-yeducacion/

Sánchez Quiroz, J. Pérez, J. (2010). Casi todos los historiadores afirman que Hidalgo tuvo descendencia. Toma. Revista Mexicana de Cine, (12), 41-43.

Scolari, C. A., Ruiz, X., Maietti, M., Bittanti, M., Lowood, H., Sáez, E., ... Martí Parreño, J. (2013). Homo Videoludens 2.0. De Pacman a la gamificación. Col-lecció Transmedia XXI. Laboratori de Mitjans Interactius. http://doi.org/10.1111/j.14678535.2011.01259.x

Wittkower, R., Polo, M., Wittkower, R., \& Greco, E. (2006). La alegoría y la migración de los símbolos. Madrid: Siruela.

Wolf, M. J. P., \& Perron, B. (2005). Introducción a La Teoría Del Videojuego. Formats. Revista de Comunicació Audiovisual, 4, 1-27. Retrieved from http://www.upf.edu/ materials/depeca/formats/pdf_arti_esp/wolf_esp_.pdf

Woodside, J. (2012). Cine y memoria cultural : la ilusión del multiculturalismo a partir de 
dos películas mexicanas de animación, XVIII, 65-84.

Alamán, L. (1985). Historia de Méjico. Desde los primeros movimientos que prepararon su Independencia en el año de 1808 hasta la época presente (Edición facsimilar de la de 1849). México: Fondo de Cultura Económica.

Benjamin, W., Weikert, A. E., \& Echeverría, B. (2003). La obra de arte en la época de su reproductibilidad técnica. México: Ítaca.

Betancourt, J. (2010). Hidalgo. La historia jamás contada. Proceso, (1770).

Calabrese, O. (1999). La era neobarroca. Catedra. http://doi.org/ISBN 8437608635

Cardoso Vargas, H. A. (2006). La mexicanidad en el libro de texto gratuito. Odiseo. Revista Electrónica de Pedagogía, 16(6), 26. Retrieved from http://www.odiseo.com. $\mathrm{mx} / 2006 / 01 /$ cardoso-mexicanidad.htm

Chust, M., Mínguez, V., Damas, G. C., Chust, M., Connaughton, B. F., Fowler, W., ... Zarate, V. (2003). La Construcción Del Héroe En España Y México ( 1789-1847 ).

Cuenca, J. M., Martín, M., \& Estepa, J. (2011). Historia y videojuegos. Iber, 69, 1-10.

Cuik, P. (2009). Diccionario de directores del cine mexicano. Tomo I. México: Instituto Mexicano de Cinematografía / Dirección General de Publicaciones.

Donskoi, M. (1981). Lenin y el cine. Madrid: Fundamentos.

Dumézil, G. (1970). The Destiny of the Kings. Chicago: The University of Chicago Press.

Eco, U. (1999). Apocalípticos e integrados. Palabra en el tiempo. Ensayo (Vol. 39).

Egenfeldt-Nielsen, S., Smith, J. H., \& Pajares Tosca, S. (2013). Understanding Video Games. Routledge.

Fabi, O. (2014). La primera construcción mítica en torno a Miguel Hidalgo *. Revista de El Colegio de San Luis, (8), 160-190.

Ferro, M. (1995). Historia contemporánea y cine. Barcelona: Ariel.

Ferro, M. (2003). The use and abuse of history (Routledge). Nueva York: Routledge.

Findling, J. (2008). Integration of Game-Based Learning into a Social Studies Curriculum Model to Improve Student Performance in the Ohio Social Studies Standards, (August). Retrieved from https://etd.ohiolink.edu/!etd.send_file?accession=bgsu $1218489507 \&$ disposition=attachment

Florescano, E. (1989). Teresa de Mier y Bustamante. Fundación del nacionalismo histórico. Nexos.

Gálvaez de la Cuesta, M. del C. (2006). Aplicaciones de los videojuegos de contenido histórico en el aula. Icono14, 7, 217-230.

García Canclini, N. (2009). Culturas híbridas. México: Debolsillo.

García Riera, E. (1999). Breve historia del cine mexicano. Primer siglo (1897-1997). México: Conaculta, Imcine, Canal 22, Universidad de Guadalajara, Ediciones MAPA.

González, L. (2006). La historia académica y el rezongo del público. Istor, VIII(29), 98-99.

Gros, B. (1998). Jugando con videojuegos : educación y entretenim iento. Bilbao: Desclée De Brouwer.

Gubern, R. (2007). Del bisonte a la realidad virtual. La escena y el laberinto. Barcelona: Anagrama.

Herrador Sánchez, J. Á., \& Morales Cevidanes, M. Á. (2012). La Constitución de 1812 y el Bicentenario de la Independencia de Iberoamérica en diferentes soportes icónicos. México: Upo Innoba.

Hueso, Á. L. (2001). La biografía como modelos histórico-cinematográfico. Historia Contemporánea, 1(22), 97-115.

Humboldt, A. D. (1975). Ensayo Político sobre el reino de la nueva España. México: Porrúa.

Jameson, F. (1985). La estética geopolítica. Cine y espacio en el sistema mundial. Barcelona: Paidos.

Juan Francisco Jiménez Alcázar. (2009). Videojuegos y Edad Media. Imago Temporis, 3, 551-587.

Lévi-Strauss, C. (2002). Mito y Significado. Madrid: Alianza.

Miquel, Á. (2010). La ficción de la historia. El siglo XIX en el cine mexicano. México: Cineteca Nacional. 
Monsiváis, C. (2000). Aires de familia. Cultura y sociedad de América. Barcelona: Anagrama.

Ramírez Zaragoza, J. A. (2012). Evaluación Del Videojuego Memorias De Una Nación Para Su Aplicación En La Enseñanza De Historia De México. Retrieved from http://congreso.pucp.edu.pe/alaic2014/grupos-tematicos/gt-4-comunicacion-yeducacion/

Sánchez Quiroz, J. Pérez, J. (2010). Casi todos los historiadores afirman que Hidalgo tuvo descendencia. Toma. Revista Mexicana de Cine, (12), 41-43.

Scolari, C. A., Ruiz, X., Maietti, M., Bittanti, M., Lowood, H., Sáez, E., ... Martí Parreño, J. (2013). Homo Videoludens 2.0. De Pacman a la gamificación. Col-lecció Transmedia XXI. Laboratori de Mitjans Interactius. http://doi.org/10.1111/j.14678535.2011.01259.x

Wittkower, R., Polo, M., Wittkower, R., \& Greco, E. (2006). La alegoría y la migración de los símbolos. Madrid: Siruela.

Wolf, M. J. P., \& Perron, B. (2005). Introducción a La Teoría Del Videojuego. Formats. Revista de Comunicació Audiovisual, 4, 1-27. Retrieved from http://www.upf.edu/ materials/depeca/formats/pdf_arti_esp/wolf_esp_.pdf

Woodside, J. (2012). Cine y memoria cultural : la ilusión del multiculturalismo a partir de dos películas mexicanas de animación, XVIII, 65-84. 